\title{
As contribuições do estágio supervisionado para a formação profissional
}

\author{
The contributions of the supervised stage to vocational training
}

\section{Las contribuciones de la etapa de formación supervisada}

\author{
Givanildo da Silva \\ Doutor em Educação \\ Universidade Federal de Alagoas - UFAL. \\ Maceió, Alagoas - Brasil. \\ givanildopedufal@gmail.com

Alex Vieira da Silva
Mestre em Educação
Universidade Federal de Alagoas - UFAL.
Maceió, Alagoas - Brasil.
alexpedufal@gmail.com \\ Inalda Maria dos Santos \\ Doutora em Educação \\ Universidade Federal de Alagoas - UFAL. \\ Maceió, Alagoas - Brasil. \\ inaldasantos@uol.com.br
}

Resumo: O objetivo do texto é apresentar reflexões sobre o estágio supervisionado na formação inicial e continuada dos estudantes de Pedagogia, tendo como referência o estágio em gestão escolar na Universidade Federal de Alagoas. A metodologia esteve pautada em uma abordagem qualitativa, por meio das pesquisas bibliográfica e documental, sendo esta última constituída pelas fichas de avaliação dos estudantes que realizaram o estágio supervisionado em gestão escolar. Como resultados, foi possível compreender o estágio como campo formativo para os estudantes, sendo composto de diferentes etapas e experiências. No caso da avaliação dos estudantes, ficou evidente que as propostas planejadas, atendendo às demandas da instituição, não foram vivenciadas devido à gestão escolar não estar de acordo, causando reflexões para os envolvidos.

Palavras-chave: Estágio supervisionado. Gestão escolar. Formação de professores. Escola pública.

Abstract: The objective of the text is to present reflections on the supervised internship in the initial and continuing education of Pedagogy students, having as reference the internship in school management at the Federal University of Alagoas. The methodology was based on a qualitative approach, through bibliographic and documentary research, the latter constituted by the evaluation forms of the students who undertook the supervised internship in school management. As a result, it was possible to understand the internship as a formative field for students, being composed of different stages and experiences. In the case of student evaluation, it was evident that the planned proposals, meeting the demands of the institution, were not experienced due to school management not being in agreement, causing reflections for those involved.

Keywords: Supervised internship. School management. Teacher training. Public school.

Resumen: El objetivo del texto es presentar reflexiones sobre la pasantía supervisada en la formación inicial y continua de los estudiantes de Pedagogía, teniendo como referencia la pasantía en gestión escolar en la Universidad Federal de Alagoas. La metodología se basó en un enfoque cualitativo, a través de la investigación bibliográfica y documental, esta última constituida por las formas de evaluación de los estudiantes que realizaron la pasantía supervisada en gestión escolar. Como resultado, fue posible entender la pasantía como un campo formativo para los estudiantes, al estar compuesto por diferentes etapas y experiencias. En el caso de la evaluación de los estudiantes, se evidenció que las propuestas planificadas, atendiendo a las demandas de la institución, no se vivieron debido a que la gestión escolar no estuvo de acuerdo, lo que generó reflexiones para los involucrados.

Palabras-clave: Prácticas supervisadas. Gestión escolar. Formación de profesores. Escuela pública. 


\section{Introdução}

O processo de identidade docente é complexo e inacabado, tendo seu início no contexto da formação inicial, quando os estudantes têm os primeiros contatos com o campo teórico e empírico da educação e suas complexidades. Desse modo, afirma-se que as práticas vivenciadas no âmbito da formação inicial são importantes experiências que contribuem para o processo de identificação da profissão docente.

As inquietações, as dúvidas, os desejos, as inspirações são sentimentos que surgem no âmbito da formação inicial, especialmente para os estudantes que nunca estiveram no espaço escolar, na condição de profissional da educação ou estagiário. A defesa que se faz para esse processo é a de que os estudantes, futuros profissionais da área, tenham contato com a escola desde o início do curso, a fim de possibilitar conhecimentos, interações, envolvimento com os dilemas e as atividades desenvolvidas nos diferentes espaços educacionais.

Para Alarcão (2008), a ida do estudante à escola é um fenômeno pertinente para a sua formação, pois o futuro profissional terá a possibilidade de encontrar-se com os atores educacionais e observar a prática deles com um olhar reflexivo na perspectiva de relacionar os saberes, as ações e as experiências. De acordo com a autora, o professor reflexivo é aquele que está atento às situações cotidianas e disposto para entrar em cena a fim de organizar práticas, dialogar e solucionar conflitos. Assim, "a noção de professor reflexivo baseia-se na consciência da capacidade de pensamento e reflexão que caracteriza o ser humano como criativo e não como mero reprodutor de ideias e práticas que lhe são exteriores” (ALARCÃO, 2008, p. 41).

A discussão sobre a formação docente perpassa diversas dimensões - política, social, cultural e educacional - que refletem na concepção de sociedade, de homem e de educação que se pretende instaurar. Esse modelo dá-se por meio das correlações de forças que são vivenciadas na arena política, ocasionando lutas e conflitos no âmbito das decisões educacionais e políticas.

Essas decisões intervêm no processo de construção de itinerários formativos para os professores em formação inicial e continuada, com a finalidade de alcançar os objetivos propostos pela lógica em curso. Desse modo, o objetivo deste texto é apresentar reflexões sobre o estágio supervisionado na formação inicial e continuada dos estudantes de Pedagogia, tendo como referência o estágio em Gestão Escolar na Universidade Federal de Alagoas (UFAL), compreendendo-o como etapa formativa que contribui para a discussão da relação entre teoria e prática no desenvolvimento das atividades educativas.

A abordagem qualitativa foi o caminho metodológico desenvolvido no estudo, tendo as pesquisas bibliográfica e documental como pano de fundo para alcançar os objetivos propostos, as 
quais contribuíram para a compreensão das principais sistematizações sobre o estágio supervisionado em questão. A revisão da Literatura foi compreendida como “o referencial teórico de um pesquisador pelo qual ele enxerga a realidade, sugerindo perguntas e indicando possibilidades" (LUNA, 2000, p. 32). Ela foi uma importante parte da pesquisa a ser desenvolvida, uma vez que o levantamento de discussões sobre a temática em questão seria a melhor estratégia para o início das problematizações.

Foram utilizadas fichas avaliativas (documento sistematizador) pelos estudantes do curso de Pedagogia da UFAL para a compreensão do olhar dos acadêmicos sobre o estágio em gestão escolar. A análise documental foi relevante, pois, por meio dela, foi possível fazer reflexões sobre o objeto de estudo. Na visão de Fonseca (2002, p. 32), a pesquisa documental "recorre a fontes mais diversificadas e dispersas, sem tratamento analítico, tais como: tabelas estatísticas, jornais, revistas, relatórios, documentos oficiais, cartas, filmes, fotografias, pinturas, tapeçarias, relatórios de empresas, vídeos de programas de televisão, etc.”. Através desse pressuposto, as fichas avaliativas de estudantes do $4^{\circ}$ período de Pedagogia da UFAL, campus A. C. Simões, semestre 2018.1, serviram como base para as análises e as interpretações do estágio supervisionado.

Para a interpretação dos dados, optou-se pela Análise de Conteúdo (AC), na perspectiva de Bardin (2002), visto que "é um conjunto de técnicas de análise das comunicações visando obter, por procedimentos, sistemáticos e objetivos de descrição do conteúdo das mensagens, indicadores que permitam a inferência de conhecimentos relativos às condições de produção destas mensagens" (BARDIN, 2002, p. 42).

O texto está estruturado em três partes que se completam, além da introdução e das considerações finais. Na primeira, apresenta-se uma discussão sobre a gestão escolar como ponto de partida para a concretização de aprendizagens e experiências democráticas, tendo como referências os dispositivos jurídico-normativos da educação brasileira; $\mathrm{Na}$ segunda parte, reflete-se sobre o papel do estágio supervisionado no contexto da formação docente e a relação intrínseca da teoria e da prática para o diálogo e a compreensão do campo pedagógico. Por fim, analisa-se o estágio em Gestão Escolar, por meio das vozes de estudantes, do $4^{\circ}$ período do curso de Pedagogia da UFAL, do semestre letivo 2018.1.

\section{A gestão escolar como lócus de experiência democrática}

A educação é um campo em construção (SILVA, 2015) e está em constantes mudanças que repercutem no "chão" da escola e nas atividades realizadas pelos profissionais da área. Essas mudanças são ocasionadas pelas perspectivas políticas instauradas pelos governantes, tendo, como 
dimensão, a construção de um modelo de sociedade pautado pelo viés ideológico e político arraigado em suas bases epistemológicas.

É válido destacar que a educação também é um campo político (APPLE, 2001), portanto, é complexo e contraditório. Os princípios apresentados nos dispositivos legais são resultados de contradições e de lutas que se instauraram no contexto político-social e refletem as forças e as concepções de educação e de gestão escolar postas no "chão" da escola pública.

A concepção de gestão escolar defendida nos dispositivos legais da educação brasileira é a gestão democrática. Esta, por sua vez, é entendida como o mecanismo que possibilita a ação coletiva dos diferentes segmentos no processo de decisão, tendo o conselho escolar como o órgão máximo nas tomadas de decisão, sendo que o gestor escolar é o mediador e o organizador do processo democrático e participativo. De um modo geral,

[...] para que os fundamentos do novo paradigma constitucional, que preconiza uma educação democrática, emancipadora, cidadã, possam desfazer os do antigo paradigma patrimonialista, é necessário que as "comunidades escolar e local" adotem a estratégia de participar efetivamente nos conselhos, com autonomia para exercer seu poder cidadão na gestão das instituições públicas de educação, tendo como pressuposto que essas instituições pertencem a cidadania (BORDIGNON, 2005, p. 6).

A concepção da gestão democrática é resultado de lutas, de tensões e de embates dos movimentos sociais e de educadores que desenvolveram ações de resistências ao processo de subordinação e de indicação dos gestores e organizadores escolares. Esses movimentos, após o processo de reabertura política na década de 1980, envolveram-se em discussões para que a Carta Magna, que estava em processo de elaboração, pudesse apresentar uma nova concepção de educação e, consequentemente, um paradigma de gestão escolar condizente com a concepção em construção.

Os debates e as ações foram travados a partir da organização de seminários efetivados no âmbito federal, tendo como objetivo discutir quais seriam os possíveis caminhos para conquistar mudanças no âmbito da educação, com garantias normativas. Desses embates, resultaram nove artigos na Constituição Federal, os quais apresentam as formas de organização da educação brasileira. Entre eles, no artigo 205 da CF/1988, no inciso VI, está a gestão democrática como concepção defendida a ser vivenciada nas escolas públicas.

Uma vez garantida a concepção de gestão escolar democrática na CF/1988, a luta dos profissionais da educação e dos movimentos em prol de uma educação pública para todos foi a concretização desse paradigma no chão da escola, pois “esses dispositivos legais, por si só, não mudam cultura e valores. Somente as práticas iluminadas pelo novo paradigma podem mudar culturas e valores" (BORDIGNON, 2005, p. 6). Desse modo, a construção de conselhos escolares, 
Projetos Político-Pedagógicos, criação de associação de pais e mestres, grêmios estudantis, foram mecanismos propícios para a mudança gradativa dessa concepção.

É válido destacar que a defesa do paradigma da gestão democrática é recente, tendo muitas redes que ainda não vivenciam esse princípio educacional, uma vez que a cultura da indicação política, do conservadorismo e do mandonismo ainda é forte em grande parte dos 5570 municípios brasileiros, principalmente nos menores e nos interiores das regiões brasileiras. Nesse contexto, a luta e a defesa pela gestão democrática é constante e requer a participação ativa de todos que buscam um espaço público, gratuito, democrático e referenciado socialmente, como dimensão cultural e educacional para todos.

Na visão de Cury (2006, p. 16):

A ordem jurídica de caráter democrático se impôs como um todo, aí compreendida a área educacional. Por isso, a ordem constitucional que nasceu em 1988 consagrou princípios caros a democracia e a educação democrática. Ela é tanto um modo de se opor ao que até então vigorava em termos de medo e de despotismo, quanto uma maneira de se propor a gestação de uma nova maneira de se administrar a coisa pública.

Nessa configuração da política educacional e dos dispositivos legais, em 20 de dezembro de 1996, foram aprovadas as Diretrizes da Educação Brasileira, Lei 9.394. A LDB foi resultado de muitos entraves no Congresso Nacional, pois diferentes grupos tinham perspectivas divergentes de educação, apresentando projetos educacionais distintos. No entanto, mesmo resultando desse cenário de conflitos, a concepção de gestão escolar pautada na legislação foi a gestão democrática, a qual, no artigo 14, salienta dois princípios para a sua efetivação: I - participação dos profissionais da educação na elaboração do projeto pedagógico da escola; II - participação das comunidades escolar e local em conselhos escolares ou equivalentes (LDB/1966).

A defesa pela existência de um conselho escolar nas escolas públicas ratificou o caráter democrático apresentado na $\mathrm{CF} / 1988$ e direcionou a visibilidade do processo decisório para o conselho escolar e não mais, apenas, para o gestor, o qual culturalmente tinha o poder final de decisão das práticas educativas. Silva e Magalhães (2019, p. 158) apresentam que:

Dentre os diversos mecanismos de vivência de consolidação da gestão democrática na
escola pública, a ação efetiva do CE destaca-se como um elemento relevante nas decisões
pedagógicas, administrativas e financeiras, isso porque o CE tem o papel de contribuir
no processo organizativo de todas as dimensões da escola, possibilitando que diferentes
segmentos estejam envolvidos nos aspectos globais da organização escolar. Dentro desse
contexto, percebe-se a importância da existência do CE, pois suas ações apresentam
benefícios de responsabilidade por um espaço educativo público de boa qualidade.

Além da relevância atribuída ao conselho escolar, a LDB/1996 também salientou o legado da construção coletiva do Projeto Político-Pedagógico das escolas, sendo necessário que cada instituição vivencie esse momento, a fim de possibilitar a discussão e a construção da identidade 
da escola por meio da concepção de sociedade, de homem, de educação e de escola que se pretende vivenciar, de modo democrático e participativo. Nessa lógica, o projeto pedagógico da escola não pode "ser concebido como um simples documento para ser guardado na gaveta, ele necessita de constantes revisões e avaliações pelos vários segmentos da escola, a fim de assegurar a dinamicidade em relação aos desafios permanentemente apresentados ao trabalho pedagógico" (SOUSA; CORRÊEA, 2002, p. 53).

Assim, pode-se considerar que os alicerces para a vivência da gestão democrática no "chão" da escola pública estão na possibilidade da participação e no processo de elaboração da proposta pedagógica, a qual conduzirá as práticas educativas, salientando ações e princípios no direcionamento dessas questões. Na visão de Cury (2005, p. 18):

A gestão democrática é um princípio do Estado nas políticas educacionais que espelha o
próprio Estado Democrático de Direito e nele se espelha, postulando a presença dos
cidadãos no processo e no produto de políticas dos governos. Os cidadãos querem mais
do que ser executores de políticas, querem ser ouvidos e ter presença em arenas públicas
de elaboração e nos momentos de tomada de decisão. Trata-se de democratizar a própria
democracia.

A atuação dos atores é o mecanismo para a existência da gestão democrática na escola e nos diferentes espaços, os quais demandam decisão política. A política educacional, neste sentido, torna-se uma dimensão que necessita da participação de todos os segmentos sociais, a fim de construir coletivamente ações para a educação. Dessa forma, em 25 junho de 2015, foi aprovado o Plano Nacional de Educação, Lei 13.005, cuja vivência será até 2024 e tem como objetivo traçar metas para a melhoria da educação nos próximos anos.

O atual Plano Nacional de Educação (2014/2024) é a referência para a política educacional, uma vez que apresenta ações para serem vivenciadas em todas as esferas da educação. No âmbito da gestão escolar, a meta 19 valida o paradigma da gestão a ser desenvolvida nas escolas públicas, por meio das diferentes experiências democráticas no âmbito escolar e educacional. O PNE é uma política de Estado, logo precisa ser referência na construção das ações a serem vivenciadas para consolidar a sua força e a sua importância, enquanto planejamento da educação.

Percebe-se que os aspectos legais que normatizam a educação brasileira sinalizam para a relevância da concepção da gestão democrática, mesmo em meio aos conflitos e distintas configurações políticas que foram se estruturando durante as três décadas de existência da Carta Magna. Cabe ressaltar que esse paradigma, na atualidade, é uma questão de resistência, uma vez que a força e a disposição dos movimentos organizados podem despertar a vivência de práticas educativas que motivem melhorias educacionais, possibilitando a concretização da educação pública para todos, defendida pelos movimentos sociais e políticos na década de 1980. 
No “chão" da escola pública, o paradigma de gestão escolar democrática pode confundirse com questões de centralização, autoritarismo, eleição de diretor, enfim, há inúmeras metamorfoses que escondem o caráter da concepção apresentada nos dispositivos jurídiconormativos. A concepção da participação e da defesa de uma escola aberta para a comunidade local pode ser direcionada por práticas de centralização das decisões na figura exclusiva do gestor, pois os princípios defendidos nos marcos legais são caros na cultura escolar, especialmente, na realidade alagoana, lugar marcado pelo coronelismo e pela subordinação da população aos políticos locais (SILVA, 2016).

Cabe fazer a defesa da escola como espaço democrático, com enfoque na participação de todos os segmentos com a finalidade de pensar acerca dos desafios enfrentados no espaço escolar, uma vez que, nesse local, acontecem as práticas diárias de ensino e de aprendizagem. A valorização da escola, como ponto de partida para o processo de vivências e de construções democráticas, demonstra a importância desse lugar, enquanto espaço formativo de saberes, de experiências e de inspirações.

\section{O papel do estágio supervisionado no contexto da formação docente}

O estágio supervisionado é considerado como campo de reflexão (PIMENTA, 2012) sobre as práticas educativas no processo de formação dos estudantes de licenciaturas. Através do contato direto com o espaço escolar, os sujeitos podem ter uma visão geral sobre a escola, seus conflitos, sua organização, sua dinâmica e as múltiplas possibilidades de experenciar a educação em tempos difícieis.

De acordo com Pimenta e Lima (2012), o estágio supervisionado não pode ser reduzido a apenas instruções técnicas profissionais, mas é necessário que essa experiência contribua para a concretização de ações reflexivas sobre o espaço escolar, portanto, a escola deve ser o ponto de partida para a formação docente, compreendendo-a como espaço coletivo, dinâmico, multicultural e dialógico. Para as pesquisadoras (2012, p. 102):

\footnotetext{
Os conhecimentos e as atividades que constituem a base formativa dos futuros professores têm por finalidade permitir que estes se apropriem de instrumentais teóricos e metodológicos para a compreensão da escola, dos sistemas de ensino e das políticas educacionais. Essa formação tem por objetivo preparar o estagiário para a realização de atividades nas escolas, com os professores nas salas de aula, bem como para o exercício de análise, avaliação e crítica que possibilite a proposição de projetos de intervenção a partir dos desafios e dificuldades que a rotina do estágio nas escolas revela.
}

Os estudos de Shön (2002); Alarcão (2008); Pimenta (2012); e Nóvoa (2007) apresentam que as formações inicial e continuada dos professores devem estar pautadas em uma dinâmica 
dialógica, tendo os processos educativos e suas complexidades como panos de fundo da teia educacional, possibilitando que os profissionais tenham experiências de resolução de conflitos e estratégias para solucionar os dilemas que surgem no cotidiano escolar.

A relação entre concepção de educação e formação docente está atrelada aos paradigmas instaurados no cenário político e social, contribuindo para as relações postas no espaço escolar. Assim, é necessário que as formações inicial e continuada dos docentes sejam realizadas em uma perspectiva crítica, dialógica, inclusiva e reflexiva, com a finalidade de que esses profissionais possam ter conhecimento sobre as intenções das políticas e de suas propostas.

Desse modo, o estágio supervisionado desenvolve um importante papel no processo de formação docente. Suas implicações estão na possibilidade de o estudante estar em contato direto com a escola e os seus profissionais, em uma dimensão dialógica e na troca de saberes entre os envolvidos. A análise do espaço escolar e a vivência de práticas com os pares favorecem aos estudantes autonomia no processo de reflexão sobre o espaço escolar, construindo sua identidade por meio das experiências coletivas.

De acordo com Pimenta e Lima (2012), o estágio supervisionado é o espaço de entrelaçamento de saberes e de experiências que se congregam ao processo formativo dos envolvidos, uma vez que suas ações favorecem a compreensão da dinâmica escolar, do processo de identidade docente e das inspirações para o campo da profissão docente. Para as pesquisadoras, o estágio supervisionado também é a dimensão que interliga a universidade e a escola, favorecendo trocas de experiências e consolidando a função social na formação integral dos envolvidos, isso porque a escola, como instituição pública, também tem o papel de contribuir no processo de formação dos futuros docentes, implementando uma via de mão dupla na construção social da formação docente.

Pimenta e Lima (2012, p. 112) destacam:

\begin{abstract}
É necessário, pois, que as atividades desenvolvidas no decorrer do curso de formação considerem o estágio como um espaço privilegiado de questionamento e investigação. A aproximação do aluno estagiário com o professor da escola não é apenas para verificar aula e o modo de conduzir a classe. É também para pesquisar a pessoa do professor e suas raízes, seu ingresso na profissão, sua inserção no coletivo docente, como conquistou seus espaços e como vem construindo sua identidade profissional ao longo dos anos.
\end{abstract}

Nessa lógica, a compreensão que se tem do estágio supervisionado é a de que a cultura escolar e suas interfaces estão no centro das experiências, isso porque o contato com a escola viabiliza conhecimentos sobre a proposta pedagógica, as responsabilidades dos diferentes profissionais e as intencionalidades educacionais. O estágio, como atividade intencional, favorece a vivência da práxis escolar que se dá por meio da relação intrínseca entre teoria e prática. É preciso 
compreender que essas dimensões estão interligadas e favorecem a vivência de ações educativas que contribuem para a aprendizagem.

Nessa dimensão, a práxis educativa consolida-se quando a reflexão sobre a ação está presente nas propostas educativas, tendo, como embasamento teórico-metodológico, as discussões e as experiências realizadas no campo da academia. No caso específico do estágio supervisionado, os estudantes, por meio de suas experiências acadêmicas, dialogam e refletem sobre a realidade escolar através dos saberes mediados com as demais disciplinas no curso de graduação, uma vez que "a identidade se constrói com base no confronto entre as teorias e as práticas, na análise sistemática das práticas à luz das teorias, na elaboração de teorias, o que permite caracterizar o estágio como um espaço de mediação reflexiva entre a universidade, a escola e a sociedade" (PIMENTA; LIMA, 2012, p. 112).

A partir desse ponto de vista, é válido destacar que a integração dos saberes dos demais componentes curriculares torna-se um elemento vivo para a experiência do estágio e da compreensão dos estudos sobre a importância da relação teoria e prática, como campo interligado e indissociável. Quando se analisam as experiências, as práticas e os saberes vivenciados na escola sob esta ótica, pode-se refletir sobre as questões postas com clareza e embasamento teórico-prático.

Cabe levantar a defesa, mais uma vez, de que a escola deve ser o ponto de partida para a reflexão sobre a práxis escolar e as múltiplas possibilidades formativas para os envolvidos. Em outras palavras, é preciso "caminhar para produzir processos aprendentes em que os estudantes possam se constituir como indivíduos autônomos; que se façam sujeitos capazes de renovar a democracia e se opor às denominações sistêmicas" (CARRANO, 2018, p. 79). Neste sentido, é possível afirmar que o estágio supervisionado também pode ser considerado como campo de pesquisa, através de uma perspectiva investigativa e da compreensão do processo educativo como dimensão ampla e complexa.

As discussões acerca da escola e as suas complexidades favorecem um olhar crítico sobre a prática social do educador e a compreensão das correlações de forças instauradas no "chão" da escola, isso porque a produção de profissionais exige dialógo (CARRANO, 2018), participação, produção e reflexão. O estágio supervisionado, por acontecer nesse espaço, também está presente nessa teia complexa e gera impactos no processo de organização, de compreensão e de possibilidades na formação inicial e continuada dos futuros profissionais. Dessa forma, defende-se a escola como lócus de aprendizagem e de dialógo para os profissionais em formação, por se tratar de um espaço público, democrático, laico e com inspirações de mudanças. 
No contexto do estágio supervisionado em gestão escolar, os estudantes estão inseridos no complexo movimento da gestão da escola pública, oriundo dos desafios cotidianos que os profissionais da educação vivenciam. A inserção dos estagiários na escola contribui para a compreensão dos aspectos inerentes à atuação do gestor escolar, do coordenador pedagógico e das relações existentes entre escola, comunidade escolar e local, política educacional e ações governamentais.

A formação dos estudantes por meio do estágio supervisionado em gestão escolar, tornase mais sólida e reflexiva, favorecendo a construção da identidade de um profissional da educação que busca questionar e compreender as nuances e as tensões que estão presentes na complexa colcha de retalhos que forma a educação pública. De um modo geral, a presença dos estudantes enriquece o olhar sobre as práticas e as funções de um gestor escolar, lançando luzes às inquietações profissionais, transformando dilemas em inspirações a serem vivenciadas na busca pela identidade docente.

A próxima seção trata de uma experiência de estágio supervisionado, observando as vozes dos estudantes do curso de Pedagogia da UFAL.

\section{O estágio supervisionado em gestão escolar: a escuta das vozes dos estudantes}

O curso de Pedagogia da UFAL tem quatro estágios para os estudantes - Gestão Escolar; Educação Infantil; Alfabetização e Letramento e Ensino Fundamental - os quais são realizados a partir do $4^{\circ}$ período. O estágio em gestão escolar é o primeiro do curso e tem o objetivo de possibilitar que os estudantes tenham contato com as escolas públicas e os profissionais da gestão escolar, de modo que dialoguem, interajam e compreendam a realidade e os desafios da escola, campo de atuação.

A organização do estágio em gestão escolar dá-se em três momentos. No primeiro, a turma tem discussões teóricas sobre a área com os professores supervisores na universidade. No segundo momento, os estudantes têm os primeiros contatos com a escola, fazem a caracterização e dialogam com os gestores para perceberem os entraves que são vivenciados no âmbito da gestão. Ainda nesse segundo momento, os estudantes retornam para a universidade com a finalidade de sistematizarem os achados e elaborarem um projeto de intervenção. No terceiro momento, os estudantes realizam o projeto de intervenção na escola e constróem um relatório final de estágio. No final do relatório, cada estudante faz a sua avaliação do estágio, de modo que possa apresentar a compreensão do processo formativo vivenciado no estágio supervisionado. 
SILVA, Givanildo da; SILVA, Alex Vieira da; SANTOS, Inalda Maria dos. As contribuições do estágio supervisionado para a formação profissional

Cabe destacar que os estudantes são acompanhados nas escolas por um supervisor. Cada supervisor pode ter, no máximo, 15 estudantes, sendo estes distribuídos em duas escolas. O supervisor é o responsável por fazer contato com as escolas e orientar/acompanhar todos os estudantes nas diferentes etapas do estágio.

Objetivando ouvir as vozes dos estudantes sobre o estágio em gestão escolar, seguem três avaliações de estudantes que vivenciaram esse momento formativo:

Quadro 1 - Visão sobre o estágio supervisionado

Um estágio que iríamos presenciar um ou mais dias do cotidiano de um gestor, para que além de poder fazer uma intervenção com base em um problema da escola, também poder vivenciar o que é ser gestor, suas obrigações em uma escola e como isso se dá. As organizações e as aprendizagens podem ser consideradas ótimas, porém o funcionamento e a relação deixou um pouco a desejar quando não foi possível a realização da intervenção (ESTUDANTE 1).

A visão que eu tinha do estágio seria que acompanharíamos o cotidiano da gestão da escola, o que foi diferente do planejado, a qual a proposta foi fazer um projeto de intervenção. A grande dificuldade foi a recepção que tivemos na escola, já que a gestão não aceitou o nosso projeto de intervenção. No caso da relação escola-universidade, acredito que há uma grande resistência da escola em relação à universidade, devido às experiências anteriores, negativas, e a universidade também não se mobiliza para melhorar essa relação (ESTUDANTE 2).

O estágio em uma visão geral é importante para a nossa formação enquanto pedagogas, a proposta dessa disciplina foi teoricamente bastante interessante, só deixando a desejar um pouco no aspecto prático, no que se refere ao número de visitas feitas à instituição. Pude aprender bastante a respeito do cargo do gestor e notar o quanto se exige do profissional. Durante os encontros na escola, as profissionais deixaram claro que a relação com a universidade não é recíproca (ESTUDANTE 3).

Fonte: Fichas de avaliação do estágio supervisionado em gestão escolar (Pedagogia - UFAL).

Os apontamentos dos estudantes apresentam questões importantes para serem refletidas acerca da formação dos futuros professores, por meio do estágio supervisionado. Antes de adentrar no mérito da questão, é válido destacar que a escola onde foi realizada a experiência do estágio não achou pertinente a realização do projeto de intervenção elaborado pelos estudantes, mesmo sendo uma demanda apresentada pelos gestores. Esse fato deixou os estudantes insatisfeitos, pois empenharam-se em elaborar uma proposta de intervenção na expectativa de contribuir com a escola.

O diálogo vivenciado entre os estudantes e os profissionais da escola foi satisfatório. Foi possível perceber, nas primeiras visitas à escola, que todos estavam empolgados com a interação, 
com a socialização e as possibilidades de aprendizagens que os primeiros momentos viabilizaram. Um aspecto a destacar na avaliação dos estudantes foi a discussão sobre o papel do gestor escolar e os desafios que esse profissional vivencia no cotidiano para que a escola cumpra a sua função social. Por meio da avaliação dos estudantes, foi possível observar que a relação teoria e prática esteve conectada como dimensão da práxis reflexiva.

Os apontamentos de Pimenta e Lima (2012) contribuem para a análise de que o estágio não pode ser considerado apenas como um componente isolado do currículo, mas deve integrar o corpo de conhecimentos do curso de formação de professores. Desse modo, "cabe-lhe desenvolver atividades que possibilitem o conhecimento, a análise, a reflexão do trabalho docente, das ações docentes, nas instituições, a fim de compreendê-las em sua historicidade, identificar seus resultados, os impasses que apresenta, as dificuldades” (PIMENTA; LIMA, 2012, p. 55).

Outra questão a mencionar é a resistência que algumas escolas apresentam para receber estagiários, isso porque estes modificam a rotina da instituição, bem como, na maioria das vezes, acabam julgando as ações educativas e as práticas dos diferentes profissionais, causando características negativas. Dessa forma, é preciso refletir que o estágio configura-se como dimensão de aprendizagem coletiva, portanto, todos estão em um espaço de diálogo e de envolvimento recíproco. É necessário romper as barreiras e perceber que a relação escola e universidade deve acontecer em uma via de mão dupla, constituindo importantes relações no processo de construção coletiva de aprendizagens.

A escola, como espaço democrático, inspira os estudantes a compreenderem as complexidades que existem em sua organização, também possibilitando que eles reflitam, coletivamente, sobre possíveis estratégias para a resolução das questões postas. Na persepctiva da defesa da gestão democrática, os desafios encontrados na escola pública devem ser solucionados por todos os segmentos, dando maior visibilidade ao papel da comunidade escolar e confirmando o protagonismo dos envolvidos, como sinalizam os dispositivos jurídico-normativos. 
Quadro 2 - Aspectos positivos e negativos sobre o estágio supervisionado

$\mathrm{O}$ aspecto positivo foi a organização das aulas, de modo que todos entendam a função de um gestor, a flexibilidade quanto alguns imprevistos que vieram acontecer e a disposição dos professores a responder algumas perguntas, mesmo que não esteja no horário de aula. $\mathrm{O}$ aspecto negativoo foi a indisponibilidade da escola em nos receber em alguns dias marcads e na intervenção (ESTUDANTE 1).

Os aspectos positivos foram conhecer uma nova escola e o fato dela ser em frente à universidade. E os negativos foram a recepção que tivemos por alguns membros da escola e o fato de não termos aplicado o projeto de intrevenção que tínhamos elaborado (ESTUDANTE 2).

Os pontos positivos são o conhecimento teórico repassado a respeito do cargo de gestor, a proposta diferenciada para a abordagem da prática. Já os negativos foram as poucas visitas na escola e a não concretização da proposta prática do estágio (ESTUDANTE 3).

Fonte: Fichas de avaliação do estágio supervisionado em gestão escolar (Pedagogia - UFAL).

Os estudantes destacaram que a contribuição do estágio em gestão escolar foi o conhecimento teórico adquirido nos processos de discussão da disciplina, sendo momentos oportunos para perceber a gestão escolar como dimensão complexa no campo da educação. Cabe apontar que estar na escola pública, como estagiário, também se configura como um aspecto positivo, uma vez que o diálogo com os profissionais pode favorecer aprendizagens para o processo identitário do futuro profissional.

Nesse cenário, Pimenta e Lima (2018) acrescentam ao debate a reflexão de que a identidade pode ser analisada nas perspectivas individual e coletiva. Enquanto a primeira é desenvolvida na história social do futuro profissional, a segunda é uma construção realizada no interior dos grupos e das categorias que se estruturam na sociedade (formações continuadas, sindicatos, associações, etc).

A principal apresentação sobre os aspectos negativos foi a não realização do projeto de intervenção, fazendo com que os envolvidos ficassem reflexivos sobre a importância da escola ao assumir o compromisso com a universidade de desenvolver todos os combinados, uma vez que a formação dos estudantes está em evidência.

Nessa percepção, a formação dos estudantes requer dimensões intrínsecas que necessitam de olhares e perspectivas bem próximos de suas realidades e a escola pública é o lócus privilegiado para essa ação. Cabe às universidade formarem profissionais capazes de desenvolver ações em sua área com foco nas potencialidades humanas que concebam o fenômeno educativo em sua totalidade, perspectivando formação e informação, envolvendo atividades não apenas pedagógicas, 
mas também atividades que visem à construção de possíveis alternativas de transformação social, levando em consideração os condicionantes que influenciam diretamente a sua função no âmbito escolar e educacional (ALARCÃO, 2008).

Nessa dimensão, é válido afirmar que a escola pública é um espaço de atendimento ao público que necessita dela, portanto, a aceitação para realização das atividades do estágio supervisionado é uma das ações que deve ser configurada pelos seus profissionais. $\mathrm{Na}$ visão de participação e descentralização, defendida no âmbito da gestão democrática, a escola é um espaço de todos e para todos, que necessitam desse lugar, como dimensão de aprendizagens e experiências.

As inquietações dos estudantes estiveram centradas na possibilidade de não desenvolver o projeto de intervenção, sinalizado pelos profissionais da escola, de modo que as expectativas formativas foram suprimidas com a negação da gestão escolar para a execução do projeto. Podese refletir, a partir desse fato, que a escola, como dimensão cultural e qualitativamente pública, é o espaço da inclusão, das vivências e dos erros e acertos para gerar aprendizagens, logo com a atitude da gestão para com as estudantes, foram-lhes negadas a oportunidade reflexiva e formativa de refletir sobre as ações vivenciadas. Práticas como essa vão de encontro às perspectivas defendidas nos dispositivos legais, os quais regulamentam a escola pública como dimensão democrática e participativa, qualitativamente de todos.

\section{Quadro 3 - Sugestões para melhorar a realização do estágio}

Não só entrevistar o gestor para entender o seu trabalho, mas, sempre que possível, observar seu trabalho de modo que todos aprendam as reais necessidades da escola e do trabalho do gestor (ESTUDANTE 1).

Acredito que, para o melhor desenvolvimento da disciplina, a escola deveria ser definida antes mesmo das aulas começarem, assim já sabíamos as escolas no primeiro dia de aula, principalmente se as escolas não forem perto da universidade, pois, assim, o aluno que não tivesse condições de se locomover trancaria a matéria. E ter a certeza de que a escola tem o intuito de realmente por em prática o projeto a ser elaborado (ESTUDANTE 2).

Ter mais dinâmica a respeito do cargo do gestor, como simulações de situações no cotidiano escolar, a possibilidade do graduando juntamente com o seu grupo poderem dar sugestões para as escolas que podem fazer estágio (ESTUDANTE 3).

Fonte: Fichas de avaliação do estágio supervisionado em gestão escolar (Pedagogia - UFAL).

A partir das experiências, os estudantes apontaram possíveis caminhos para melhorar a vivência do estágio supervisionado em gestão escolar, destacando-se a necessidade de dialogar e refletir não apenas com os gestores escolares, mas com outros segmentos da escola para perceber 
a complexidade macro da organização da escola e de seus processos educativos. Outra dimensão enfatizada foi a possibilidade de a escola cumprir os acordos firmados, com a finalidade de que os estudantes possam desenvolver o projeto de intervenção planejado.

A presença da universidade nas escolas públicas faz-se necessária, especialmente, no estado de Alagoas, em que há inúmeros problemas no processo de ensino e de aprendizagem e nas vivências das políticas públicas educacionais, na organização das práticas escolares e no processo de concretização de gestão escolar. Desse modo, elaborar propostas intervencionistas no âmbito do estágio supervisionado favorece novas atividades e propostas nas escolas públicas alagoanas, assim como contribui na formação dos licenciados que serão futuros profissionais no espaço escolar.

O processo formativo dos estudantes é compreendido como um aspecto complexo e reflexivo (ALARCÃO, 2008), tendo diferentes dimensões da educação (planejamento, currículo, didática, avaliação, gestão escolar, projetos didáticos) que se associam no cotidiano da formação como possibilidades de apresentar um amplo leque de situações, contribuindo para o processo de reflexão sobre a prática escolar. Eis a relevância dos estudantes estarem em contato direto com a escola pública, pois compreende-se a educação como um campo em construção (SILVA, 2015), o qual requer inovação e diferentes experiências, a fim de reconstruir práticas e/ou atividades configurando novas culturas na dinâmica escolar.

O diálogo sobre a importância do estágio supervisionado e suas contribuições para a formação profissional configura-se na defesa de que, na escola pública, essa atividade deve acontecer, pois, esse será o possível espaço de atuação do futuro profissional da educação. Nessa lógica, é relevante que as interações com o lugar, os profissionais, os estudantes sejam frequentes, confirmando as sistematizações desenvolvidas no espaço acadêmico.

O estágio na escola pública favorece, necessariamente, um olhar sobre as vivências, as experiências e os desafios que os profissionais lidam diariamente, gerando reflexões no processo formativo dos estudantes. A troca de experiência com os profissionais torna-se um aspecto importante para a construção de interpretação do lugar no qual foi pensado para todos aprenderem, dialogarem, construírem e transformarem (SILVA, 2016), qualificando-o como dimensão plural, inclusiva e democrática.

\section{Considerações finais}

As discussões tecidas contribuíram para a compreensão do estágio supervisionado como dimensão relevante no processo formativo dos estudantes. O estágio deve ser vivenciado em 
espaços públicos com características democráticas, a fim de que os envolvidos consigam sentir-se parte das propostas vivenciadas. De um modo geral, o estágio, como campo formativo, é um aspecto peculiar para o processo de reconhecimento identitário do futuro profissional da educação.

Uma vez que os estudantes estão em processo de formação inicial, cabe a vivência de experiências que contribuam para o diálogo, a interação e a possibilidade de atuação democrática no espaço escolar/de formação para que possam agir democraticamente em outros ambientes, incluindo a escola. Nessa lógica, pensar em ações democráticas no âmbito universitário, no espaço micro - sala de aula, requer construção coletiva por meio da avaliação da aprendizagem, do currículo e das relações estabelecidas entre os envolvidos, isso porque "é a cultura docente que constitui os professores como um coletivo. Este patrimônio simbólico compartilhado pelos professores, dá sentido à sua ação educativa e traduz um conjunto de crenças e princípios éticos norteadores da ação pedagógica do professor" (FARIAS, et. al., 2011, p. 70).

As experiências vivenciadas no âmbito da escola, do estágio e das oportunidades de discussão são favoráveis para a concretização de momentos de inspirações para romper com o paradigma de reprodução social e florescer faíscas de transformação, as quais viabilizam o direito à palavra e à reflexão. Faz-se necessária a defesa de construção de uma escola democrática, que não foge do debate e do diálogo, em oposição à tese de que a educação precisa ser 'neutra". Em um contexto social e político, como o brasileiro, a abertura para dar voz aos silenciados e visibilidade aos invisíveis é uma experiência contra hegemônica, apresentando contribuições no processo de formação social, cultural, educacional e político.

A abertura da escola pública para o estágio supervisionado é outra dimensão que ficou evidente na pesquisa, necessitando de maior interação e espaço para que os estagiários pudessem desenvolver a proposta planejada através da solicitação dos próprios profissionais da gestão escolar. Nessa conjuntura, cabe fazer a defesa da concepção de gestão escolar democrática, a qual favoreça interação, mediação, diálogo, descentralização e autonomia.

Desse modo, é preciso que as experiências vivenciadas no estágio supervisionado sejam pautadas em situações dialógicas e democráticas, tendo, como centro do processo formativo, os estudantes em espaços públicos. O ponto de partida para essa ação é a reflexão sobre a escola pública e os seus desafios que surgem em seu cotidiano. Cabe relembrar que a dimensão reflexiva é o fio condutor para a formação dos futuros profissionais, cultivando-lhes o hábito da práxis reflexiva e transformadora. Eis, portanto, o desafio! 


\section{Referências}

ALARCÃO, I. Professores reflexivos em uma escola reflexiva. São Paulo: Cortez, 2008.

APPLE, M. Politica Cultural e Educação. São Paulo: Cortez, 2001.

BARDIN, L. Análise de conteúdo. Lisboa: Edições 70, 2002. Trad. Luís Antero Reto e Augusto Pinheiro.

CARRANO, P. A escola pública diante do desafio de educar em relações de liberdade e convivência democrática. In: KRAWCZYK, N. (Org.). Escola Pública: tempo difíceis, mas não impossíveis. Campinas, SP: FE/UNICAMP; Uberlândia, MG: Navegando, 2018.

FARIAS, I. et. al. Didática e Docência: aprendendo a profissão. Brasília: Liber Livro, 2011.

FONSECA, J. J. S. Metodologia da Pesquisa Científica. Fortaleza: Universidade Estadual do Ceará, 2002.

LUNA, S. V. O falso conflito entre tendências metodológicas. In: FAZENDA, I. (Org.).

Metodologia da pesquisa educacional. São Paulo: Cortez, 2000.

NÓVOA, A. O regresso dos professores. Conferência: Desenvolvimento profissional de professores para a qualidade e para a equidade da Aprendizagem ao longo da vida. Presidência Portuguesa do Conselho da União Européia. Lisboa, 27 e 28 de setembro de 2007.

PIMENTA, S. G. O protagonismo da Didática nos cursos de licenciaturas: didática como campo disciplinar. XVI ENDIPE - Encontro Nacional de Didática e Práticas de Ensino - UNICAMP Campinas - 2012.

PIMENTA, S. G.; LIMA, M. Estágio e docência. São Paulo: Cortez, 2012.

SCHÖN, D. Formar professores como profissionais reflexivos. In: NÓVOA, A. Os professores e a sua formação. Lisboa: Dom Quixote, 2002.

SILVA, G. O Programa Dinheiro Direto na Escola (PDDE) como mecanismo da descentralização financeira, participação e autonomia na gestão escolar. Dissertação (Mestrado em Educação). Universidade Federal de Alagoas: Maceió, 2015. 136 p.

Recebido em: 15 abr. 2020/ Aprovado em: 16 set. 2020

\section{Cite como}

(ABNT NBR 6023:2018)

SILVA, Givanildo da; SILVA, Alex Vieira da; SANTOS, Inalda Maria dos. As contribuições do estágio supervisionado para a formação profissional. Dialogia, São Paulo, n. 36, p. 484-501, set./dez. 2020. Disponível em: https://doi.org/10.5585/dialogia.n36.17009. 


\section{Dialogia}

SILVA, Givanildo da; SILVA, Alex Vieira da; SANTOS, Inalda Maria dos. As contribuições do estágio supervisionado para a formação profissional

\section{American Psychological Association (APA)}

Silva, G., Silva, A. V., \& Santos, I. M. (2020, set./dez.). As contribuições do estágio supervisionado para a formação profissional. Dialogia, São Paulo, 36, p. 484-501. https://doi.org/10.5585/dialogia.n36.17009. 